Canadian

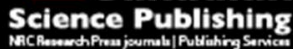

Canadian Geotechnical Journal Revue canadienne de géotechnique

\title{
Effects of grass roots on soil-water retention curve and permeability function
}

\begin{tabular}{|r|l|}
\hline Journal: & Canadian Geotechnical Journal \\
\hline Manuscript ID & cgj-2016-0281.R2 \\
\hline Danuscript Type: & Note \\
\hline Complete List of Authors: & $\begin{array}{l}\text { Jotisankasa, Apiniti; Kasetsart University, Civil Engineering } \\
\text { Sirirattanachat, Teerapat; Department of Highways, Thailand, Bureau of } \\
\text { Road Research and Development }\end{array}$ \\
\hline Keyword: & $\begin{array}{l}\text { soil-water retention curve, permeability function, grass root, soil bio- } \\
\text { engineering }\end{array}$ \\
\hline \multicolumn{2}{|c}{} \\
\hline
\end{tabular}




\title{
Effects of grass roots on soil-water retention curve and permeability function
}

\author{
Apiniti Jotisankasa ${ }^{1}$ and Teerapat Sirirattanachat ${ }^{2}$ \\ Manuscript for Canadian Geotechnical Journal
}

The effects of Vetiver grass (Chrysopogon zizanioides) roots on soil-water retention curves (SWRC), permeability (k) function and saturated permeability, $k_{\text {sat }}$, have been investigated on clayey sand (SC), and low plasticity silt (ML). For ML soil, when the root biomass per soil volume was lower than $6.5 \mathrm{~kg} / \mathrm{m}^{3}$, the saturated permeability increased, the air-entry suction slightly reduced and the SWRC became steeper with increasing root contents, probably due to the formation of cracks due to wetting \& drying cycles during plant growing period. Nevertheless, roots appeared to reduce the saturated permeability and increase the air-entry suction of ML soil, after reaching this threshold with root content of about $6.5 \mathrm{~kg} / \mathrm{m}^{3}$ as roots occupied the macro-pores and tended to suppress cracks and swelling. For SC soil for all root contents, only slight variation of the saturated permeability with root content can be observed for the upper bounds on saturated permeability. However, the lower bounds on saturated permeability appeared to decrease as root content increased. It has also been shown that for suction range beyond $30 \mathrm{kPa}$, the influence of roots on permeability appeared to be less significant.

Author Keywords: soil-water retention curve, permeability function, grass root, soil bioengineering

1 Associate Professor, Department of Civil Engineering, Kasetsart University, Bangkok, Thailand (Corresponding author)

2 Civil Engineer, Bureau of Road Research and Development, Department of Highways, formerly Department of Civil Engineering, Kasetsart University, Bangkok, Thailand 


\section{Introduction}

Vegetation has been used to prevent shallow slides and erosion in various geotechnical and geo-environmental structures, such as embankments, cover systems of landfill and mine facilities. The technique has received much attention worldwide due to its relatively low cost, aesthetic and environmental value, as well as sustainability (e.g. Coppin et al. 1990; Gray and Sotir 1996; Goldsmith et al. 2014; Bo et al. 2015). Greenway (1987) summarized various hydro-mechanical influences of vegetation on slope stability, suggesting that vegetation can exert both beneficial and adverse effects. One of the major benefits of vegetation on slope stability is through root reinforcement of soil, which is considered as additional soil strength via root cohesion (e.g. Wu et al. 1979; Nilaweera and Nutalaya 1999; Leung et al. 2015a; Jotisankasa and Taworn 2016). Vegetation can improve slope stability further through transpiration process, which in turn depletes soil moisture, increasing the soil suction and shear strength further (e.g. Indraratna et al. 2006; $\mathrm{Ng}$ et al. 2014).

The effects of vegetation roots on hydraulic properties of soil, namely soil-water retention curves (SWRC), and permeability, have been investigated by some researchers. Researchers from geotechnical engineering discipline (e.g. Huat et al. 2005, 2006; Rahardjo et al. 2014; Leung et al. 2015b, 2015c) have shown that actively growing plants could reduce infiltration rate and saturated permeability of the soil. They demonstrated grass roots tended to increase the air-entry suction and the size of hysteresis loop of SWRC. These studies highlighted the benefits of vegetation in reducing infiltration and improving slope stability.

Past research in the fields of soil science and ecology (Barley 1954; Li and Ghodrati 1994; HilleRisLambers 2001; Rachman et al. 2004; Scanlan and Hinz 2010) also suggested that, when actively growing, roots tended to block the macro-pores. Yet, they also showed that decayed roots would create more macro pore and preferential flow path. Rachman et al. (2004) demonstrated that soil from a grass hedge system, of more than 10 years old, had the 
saturated permeability of 6 to 18 times that of soil away from the hedge. These studies from soil science and ecology discipline generally highlighted the benefits of vegetation in increasing infiltration, reducing run-off, and improving quality of ecosystem in long term (e.g. Styczen and Morgan 1995). Age of roots, together with its life span and decay stage, plays an important role. Only a snapshot study at one particular root content and age may be inadequate to predict the performance of bio-engineered slope over the whole design period. Information on hydraulic properties of the soil with different root contents is very important to better predict the performance of bio-engineered slopes using numerical analyses (e.g. Rahimi et al. 2010; Rahardjo et al. 2014; Jotisankasa et al. 2014).

The purpose of this paper is to experimentally investigate the effects of vetiver grass (Chrysopogon zizanioides) on soils' hydraulic properties, namely soil-water retention curves (SWRC), and the permeability function. Two major soil types (sandy and silty) with different root contents were tested. Chrysopogon zizanioides has been widely used for bio-engineering purposes in many tropical and sub-tropical countries in South East Asia, China, Africa, South America, as well as warmer parts of the United States, Australia and Europe. Its applications range from soil-water conservation and slope stabilization (e.g. Grimshaw 1994; Hengchaovanich 1998; Truong et al. 2008; Jotisankasa et al. 2015a), as well as pollutioncontrol at landfills and wetlands (e.g. Roongtanakiat et al. 2003; Raharjo et al. 2015; Delis et al. 2015). Despite vetiver being one of the most widely used grasses in geotechnical and geoenvironmental engineering, the study of its root effects on soil-water retention curve and permeability function is very rare. 


\section{Materials}

Two major soil types were selected for investigation, namely low plasticity Silt (ML), and clayey Sand (SC). The ML soil was a residual soil derived from weathered argillaceous rock (Shale and Mudstone). It was collected from a $26^{\circ}$ slope area of fruit plantation in Uttaradit province, Northern Thailand. The vicinity of this area suffered from wide-spread shallow landslides in 2006 (ADPC 2006; Jotisankasa and Tapparnich 2010; Jotisankasa et al. 2015b). The SC soil was a completely weathered rock taken from upper part of a landslide that took place in 2011 in 1:1 cut slope of sandstone interbedded with siltstone in Ban-Natum, Suratthani, Southern Thailand (Tansamrit and Suanburi 2012; Jotisankasa et al. 2015b). These two soils represent typical materials encountered in most of bio-engineered slopes in the tropics. Their basic properties are summarized in Table 1. Tests on soil nutrients revealed that the SC soil, a completely weathered rock taken from a cut slope, was less fertile than the ML soil.

The soil specimens $(10 \mathrm{~cm}$ in diameter and $15 \mathrm{~cm}$ in height) were formed by static compaction in one layer at $80 \%$ standard Proctor maximum dry density and the optimum moisture content as summarized in Table 1. This choice of density was selected following Goldsmith et al. (2001) and Gray (2002). They suggested that an 80-85\% Standard Proctor compaction provided a compromise between requirements of shear strength and plant growth. As-compacted suction of each soil sample was also measured using miniature tensiometer and found to be above $90 \mathrm{kPa}$ for all three soils. The soil specimen's diameter of $10 \mathrm{~cm}$ was chosen such that it represented the approximate spacing between Vetiver grass clumps initially grown in hedgerows in practice. Transparent acrylic molds were used to hold the samples so root patterns could be observed directly on the mold's side. The observation of side root content can be linked to the field measurement of root using mini-rhizotron technique (e.g. Rasse et al. 2000; Rewald and Ephrath 2013; Jotisankasa et al. 2015a). Each 
of these samples was planted with three clumps of Chrysopogon zizanioides of Surathanni variety. No fertilizer was added to the soil. A small hole of less than 5 centimeter depth was dug in the middle of the soil specimen for growing the grass. The soil dug from this hole was backfilled around the grass clumps and on top of soil specimen after planting. The grasses were allowed to grow until reaching a certain age, varying from four to ten months before testing. Slight variation in quality of each grass tiller may still exist, and this may result in samples of the same growing period, yet having different root contents. Therefore, the aim of this study was to relate the hydraulic properties with root biomass content and not with the grass age.

The initial water content during planting was in the optimum condition as identified from Standard Proctor compaction test as summarized in Table 1 (i.e. 13.1\% for ML and 14\% for SC). Irrigation procedure following Truong et al. (2008) was adopted. Daily irrigation was provided during the first 15 days of growing, after which watering was done once in several days. Aluminum foil was wrapped around the transparent acrylic tube to prevent direct sunlight onto the root zone. Each sample's base was underlain by a sponge layer during plant growing period, thus allowed to drain freely. On several separate specimens, suction measurement using miniature tensiometers showed that the suction in specimen during planting varied from 2 to $80 \mathrm{kPa}$.

\section{Testing methods}

Once the root area, as appeared on the mold's side, reached a desired amount ranging from about 5 to $15 \%$ of total area, the specimen was considered ready for hydraulic tests. All the grass's leaves were then trimmed to minimize plant transpiration during test. The test program involved first soaking the sample under water for about 4 days before the drying Instantaneous Profile (IP) test, whereby soil suction increased from zero to about $100 \mathrm{kPa}$ at 
the end of test. After the completion of IP test, the sample was re-soaked for 4 days prior to the saturated permeability test. This testing sequence was necessary since the saturated permeability test involved additional trimming all the grass stump on top of the sample to ensure better flush surface and sealing all the gaps on sample mold with silicone sealant. Such manipulation during saturated permeability test made it more difficult to perform the IP test afterward. As a result, the drying IP test was carried out prior to the saturated permeability test.

The drying IP test was used for determining the SWRC and unsaturated permeability function. The IP method is a transient testing technique whereby flow rate through a soil specimen (or a soil profile) varies with time during test (e.g. Hamilton et al. 1981; Krisdani et al. 2009; Ng and Leung 2012). Profiles of water content and suction at several points along the specimen are normally monitored at fixed time intervals in order to compute the flow rate, hydraulic gradient and permeability at different suctions.

The experimental set up of the drying IP test in this study is shown in Figure 1. This set up was similar to the simplified evaporation IP method proposed by Peters and Durner (2008). The top surface of soil sample was left exposed to ambient air to induce upward onedimensional flow due to evaporation. The sample's base was underlain by an impermeable solid plate. Since all the grasses had been trimmed prior to test, no transpiration due to grass would take place and it was expected to be no localized increase in suction around the root zone. Typical results of a drying IP test are shown in Figure 2. Profiles of soil suction were monitored continuously using miniature tensiometers (Jotisankasa et al. 2007) at three locations on sample's side, as shown in Figure 2a and Figure 2e. The accuracy of tensiometer obtained during calibration was $\pm 0.15 \mathrm{kPa}$. The sample's weight was continuously measured using a data-logging balance (measuring to $0.01 \mathrm{~g}$ precision), as shown in Figure $2 \mathrm{c}$, in order to calculate the total flow rate across the sample. 
The values of suction at three locations were used to calculate the hydraulic gradient, $i$, as follows;

$$
i=\frac{d\left(h_{e}-s / \gamma_{w}\right)}{d z}
$$

where $h_{e}$ is the elevation head at each tensiometer location, $s$ is matric suction, $\gamma_{w}$ the unit weight of water and $z$ the elevation as shown in Figure 1. The value of hydraulic gradient, $i$, presented in Figure $2 \mathrm{~b}$, was computed using linear regression over the three suction measurements as demonstrated in Figures $2 \mathrm{e}$ and $2 \mathrm{f}$. All the values of $\mathrm{R}^{2}$ appeared to be greater than 0.85 suggesting reasonable goodness of fit and linearity. It is noted that during evaporation, the relation between total head and elevation can be non-linear as the suction at the top increased beyond $100 \mathrm{kPa}$. It was therefore considered the test results after top suction reached $100 \mathrm{kPa}$ unreliable and filter out those results from interpretation. As pointed out by Peters and Durner (2008) and later confirmed by Mairaing et al. (2012), linearization of the hydraulic gradient only lead to minor errors in hydraulic conductivity measurement, even in the late stage of evaporation where pressure head profiles are strongly non-linear.

The discharge velocity, $v$, at any particular time as presented in Figure 2d, was computed as follows;

$$
v=\frac{d V_{w}}{A \cdot d t}
$$

where $d V_{w}$ is the change of volume of water in soil sample calculated from change in soil mass during test as shown in Figure $2 \mathrm{c}, A$ is the cross section area of sample, and $t$ is the elapse time. Linear regression is used to calculate the slope between water volume change with time. The value of permeability at any suction and volumetric water content can then be calculated using Darcy's law,

$$
k=\frac{v}{i}
$$


It is noted that drying IP test was carried out in this study as opposed to wetting IP test. Based on the current testing technique, results of wetting test have been shown by Mairaing et al. (2012) to be less accurate than drying test. This was due to larger non-linearity of the pore water pressure distribution with depth in wetting test.

The SWRC was determined by the drying IP test by plotting the calculated volumetric water content with suctions measured from three locations. It was also compared with the SWRC determined using the point-wise method (Mairaing et al. 2012). The point-wise method involved incremental measurement of soil suction at different moisture contents. After each suction measurement, the sample is either dried or wetted, depending on the test type, by about $1 \%$ water content in order to obtain suctions at different moisture contents. Drying is realized by exposing the sample in the air, while wetting is achieved by directly adding water into the sample using a very fine spray. After changing the moisture content to a desired amount, the sample was carefully wrapped and cured for equilibration of the suction throughout the sample. A minimum curing period of about 2-3 days between each increment was allowed for. It is noted that point-wise SWRC tests were carried out on compacted sample with $63 \mathrm{~mm}$ diameter and $20 \mathrm{~mm}$ height, which was smaller than the drying IP specimens. The smaller sample size was chosen to speed up the suction equilibration time and shorten the test duration.

Figure 3 compares the SWRCs obtained from point-wise tests with those from drying IP tests. The volumetric water contents were plotted against suctions from all three tensiometers in the drying IP tests. For ML sample, SWRCs from the three tensiometers appeared to be similar. For SC sample, the SWRC based on the middle tensiometer indicated a better agreement with the SWRC from point wise test. The SWRC based on the middle tensiometer was considered a reasonable representation of the SWRC of the whole sample 
and will be presented hereafter. In general, there is a good agreement between SWRCs from the drying IP test and point-wise test.

After the drying IP test was completed, the specimen was soaked under water again for 4 days, prior to the saturated permeability test. Upper part of the sample, about $5 \mathrm{~mm}$ in thickness, was then trimmed in order to have a flush top surface. The test procedure similar to the ASTM D2434 was followed to determine the saturated permeability. Prior to each test, the soil sample was flushed by flowing water of about 1.2 meter water head, until no air bubble could be observed from the base outlet. During the test, the sample was subjected to pressure head of 1.4 meter. This choice of pressure head corresponds to the likely field condition where depth of the root zone may be limited to 1 to 1.5 meter with similar pore water pressure when fully submerged or infiltrated with rain water.

It is noted that the flexible wall method (ASTM D5084-10) could not be adopted in this study due to the difficulty in handling sample during rubber membrane sheathing without disturbing the roots. The constant head procedure was adopted for testing the sandy SC specimens, while the falling head technique was employed for the more fine-grained $\mathrm{ML}$ sample. Three orifices on the mold side, previously used for tensiometer installation, were plugged with plastic bungs and all the joints were sealed with silicone adhesive. Water tightness was carefully checked during saturated permeability testing.

\section{Measurement of root content}

In this study, root contents were directly measured in terms of "root biomass per soil volume", $\rho_{R}, \mathrm{~kg} / \mathrm{m}^{3}$. After completion of the saturated permeability test, the specimen was dismantled and the final moisture content of soil was determined. The remaining soil was washed with water and passed through Sieve \#18 (1 mm openings) to expose roots. Roots that were washed away and passed through Sieve \#18 were considered small and not included in 
root measurement. Figure 5 shows a specimen and its exposed roots. These roots were then dried in the oven at $105{ }^{\circ} \mathrm{C}$ overnight to determine their dry biomass of roots, used for calculating the "root biomass per soil volume", $\rho_{R}, \mathrm{~kg} / \mathrm{m}^{3}$. This oven-drying temperature was in accordance with recommendation by Böhm (1979). Table 2 summarizes the root contents for all samples.

\section{Phase relationships considering roots}

Soil containing roots consists of materials in four phases, including solid grains, water, air, and roots. Since roots are of different specific gravity to the solid grains, the new phase relationships considering roots are defined as follows;

$$
\begin{aligned}
& n=\frac{V_{v}}{V}=\frac{V-V_{s}-V_{r}}{V}=\frac{V-\frac{W_{S}}{G_{s} \cdot \gamma_{w}}-\frac{W_{r}}{G_{R} \cdot \gamma_{w}}}{V} \\
& \theta=\frac{V_{w}}{V}=\frac{\left(W-W_{r}-W_{S}\right)}{V} \cdot \frac{1}{\gamma_{w}}
\end{aligned}
$$

, where $n$ is porosity, $V$ is total volume, $V_{v}$ is void volume, $V_{s}$ is volume of soil particles, $V_{r}$ is volume of roots, $V_{w}$ is water volume, $W$ is total weight, $W_{s}$ is weight of soil particles, $W_{r}$ is weight of roots, $\gamma_{w}$ is water unit weight, $\theta$ is volumetric water content, $G_{S}$ and $G_{R}$ are the specific gravity of the soil grain and root respectively. Designations of all phase variables are illustrated in Figure 5. The value of root density was assumed to be $641 \mathrm{~kg} / \mathrm{m}^{3}$, according to Gray and Sotir (1996). These formulations were derived based on the fundamental phase diagram of multi-component materials (e.g. Landva and Clark 1990; Oweis and Khera 1998; Jotisankasa 2001). They give a better representation of those voids which are unoccupied by the roots, the parts which directly influences hydraulic properties of the soils. A similar formulation has been presented in $\mathrm{Ng}$ et al. (2016). 


\section{Effects of roots on saturated permeability}

Figure 6 and Table 2 show variation of saturated permeability, $k_{\text {sat }}$, with root contents for the two soils. Trend lines and error bars for the permeability values have been drawn in Figure 6 corresponding to the $80 \%$ confidence interval. In other words, about $80 \%$ of the test result population is expected to lie within these two trendlines. This confidence interval was calculated based on parameters in Table 3 following the statistical method by Clewer and Scarisbrick (2001). Due to the limited population size (sample number, $n=2-3$ ), only $80 \%$ confidence interval could be proposed. It is noted a higher confidence level (e.g. 95\%) could be achieved if more specimens were available. Those samples of similar root biomass content were considered as replicates belonging to the same group of treatment. Since permeability of most soils has been reported to have log-Normal statistic distribution (e.g. Benson 1993; Baecher and Christian 2003), the permeability data had been transformed to logarithmic values, and subsequently used for determining the standard error and the $80 \%$ confidence interval using the t-distribution, based on each group's sample size, n, as shown in Table 3.

As shown in Figure 6a, when the root biomass per volume, $\rho_{R}$, increased to about 6.5 $\mathrm{kg} / \mathrm{m}^{3}$, the permeability of the ML soil appeared to increase up to 2 to 5 times the original permeability of soils without roots prior to grassing. This was expected to be due to desiccation cracks and preferential flow induced by drying \& wetting cycles (Albrecht and Benson 2001; Li et al. 2016), as experienced during plant growth. As the root amount exceeded the threshold of $6.5 \mathrm{~kg} / \mathrm{m}^{3}$, the permeability of ML soil decreased and became nearly one order of magnitude smaller when $\rho_{R}$ was about $8 \mathrm{~kg} / \mathrm{m}^{3}$. Roots would have significantly occupied macro voids at this stage.

For the SC soil (Fig. 6b), despite the scatter in data, the lower bound of $k_{\text {sat }}$ value tended to decrease by $20-90 \%$ once the root biomass per volume, $\rho_{R}$, increased to about 6 $\mathrm{kg} / \mathrm{m}^{3}$, probably due to root occupying the pores. The upper bound of $k_{\text {sat }}$ value nevertheless 
appeared to be relatively constant. No significant increase in permeability in this range of root contents was observed for the SC soil, probably due to its more coarse-grained nature and less desiccation shrinkage tendency. Interestingly, once the root content became more than $8 \mathrm{~kg} / \mathrm{m}^{3}$ (Sample SC-1) the $k_{\text {sat }}$ value of SC soil rose back to the same range of the soil without root. It was expected to be due to root decay, as no fertilizer was added it the specimen and its nutrients would have been depleted over the growing period. Depletion of the nutrients in the specimen would have induced the roots to be more active in searching for food, resulting in greater root content. As root decayed, preferential flow path along the impoverished roots may have happened. Since this observation was only based on one sample (SC-1), no confidence level can be drawn for this root content and the root decay explanation is not yet conclusive. Still, it is noteworthy that the SC soil had lower nutrients than the ML soil as shown in Table 1 and thus root decay would have started earlier for the SC soil.

Four main phenomena during plant growth that would have affected soils' permeability can be inferred. Firstly, cycles of wetting and drying due to plant watering and evapotranspiration would tend to increase the permeability. This effect is more significant for fine-grained material such as ML at early stage of plant growth. The second is the occupying of macro-pore by plant roots which tend to decrease the permeability. The third is the decay of roots which would generate preferential flow paths along the impoverished roots, thus increasing the permeability. The fourth would be related to organic carbon released by plant roots in the form of polymeric gel (the so-called root exudation, mucilage, or rhizodeposition) which were reported to decrease the mobility of clay colloids and enhance water retention around the roots (e.g. Grayston et al. 1997; Traoré et al. 2000; Kroener et al. 2014; Tian et al. 2015; Ghezzehei and Albalasmeh 2015). Recent work by Bengough (2012) shows that some of these root exudations exhibit hydrophobic or hydrophilic behavior, depending on the soil water content, causing the hysteretic-like behavior. It is difficult to quantify variation of each 
of these effects with time. Yet it can be said that there are both effects of increasing and decreasing saturated permeability due to the presence of roots during the course of plant life.

\section{Effects of roots on soil-water retention curves}

Figure 7 shows the SWRCs of ML specimens with various root contents. As explained previously, these curves were obtained using suction reading from the middle tensiometer which represented the average suction in the sample. The air-entry suction was determined from the intersection point of the horizontal line through soaked volumetric water content and the tangent to SWRC after desaturation point. These air-entry values corresponding to each SWRC are summarized in Table 2 and plotted in Figure 8 against root biomass. As root biomass increased up to $6.5 \mathrm{~kg} / \mathrm{m}^{3}$, the air-entry suction of ML soils appeared to decrease slightly (from 2.3 to $0.7 \mathrm{kPa}$ ), probably due to micro-cracks induced by wetting \& drying cycles. Specimens with micro-cracks would desaturate at a lower suction than those without. The micro-crack explanation is also supported by the corresponding initial increase in permeability as shown in Figure 6, as explained earlier. This observation is similar to previous studies (e.g. Peng et al. 2007; Bodner et al. 2013; Ma et al. 2015), which revealed the increase in large pore induced by wetting $\&$ drying cycles as a consequence of crack and micro-crack formation. After the threshold of root biomass, $\rho_{R}$, of about $6.5 \mathrm{~kg} / \mathrm{m}^{3}$, was exceeded (Sample ML-1, ML-2), the air-entry suction appeared to increase slightly (from 0.7 to $1.8 \mathrm{kPa}$ ) perhaps due to the occupying of pores by the roots. The soaked volumetric water content, $\theta_{s}$, is defined as the water content of the specimen after soaking for 4 days prior to the IP drying test. It is noted that soaking specimens for 4 days may not necessarily bring the sample to full saturation $\left(S_{r}=100 \%\right)$ due to the presence of occluded air that requires positive pressure to dissolve (Hillel 1998; Lu et al. 2014). Therefore, the soaked volumetric water content, $\theta_{s}$, is slightly less than the porosity, $n$. Nevertheless, it is very certain that 
there was no suction in soil specimens after 4 days of soaking, as confirmed by the tensiometer reading at the start of drying IP tests. Expectedly, as positive pore water pressure increases, the volumetric water content will increase from the soaked condition towards the fully saturated condition or the value of porosity. This behavior is of great practical significance for prediction of rainfall-induced landslide or embankment failure due to infiltration or groundwater rise.

Figure 8 shows the variation between porosity and soaked volumetric water content with root biomass, as calculated from measured volume and mass of soil and roots using Equations 4 and 5. As root biomass increased and occupied more void space, the porosity decreased accordingly. The soaked volumetric water content, $\theta_{s}$, also decreased but remained close to the porosity, (i.e. degree of saturation in soaked condition being nearly $100 \%$ ) up to root biomass, $\rho_{R}$, of about $8 \mathrm{~kg} / \mathrm{m}^{3}$. At this value of $\rho_{R}$, the soaked volumetric water content, $\theta_{s}$, became lower than the porosity, indicating more occluded air in the sample with high root content.

Figure 9 shows the SWRCs of clayey Sand (SC) with various root contents, obtained from the middle tensiometer. The variation between porosity and soaked volumetric water content, $\theta_{s}$, with root content, as calculated from measured volume and mass of soil and roots using Equations 4 and 5, are shown in Figure 10. Again, porosity appeared to decrease with root content. Some increase in the soaked volumetric water content, $\theta_{s}$, with roots could be observed for Samples SC-3 and SC-4. The observed increase in $\theta_{S}$ is similar to findings of previous SWRC tests on sandy materials with roots by Rahardjo et al. (2014) and Leung et al. (2015). This increase in $\theta_{s}$ of these samples with roots may be attributed to root exudation. As explained earlier, the compound exuded around the roots tends to enhance water retention (i.e. increase in volumetric water content near saturation point in Figure 9) and decrease the mobility of clay colloids (i.e. decrease of permeability as shown in Figure 6). Once the root 
biomass exceeded $8 \mathrm{~kg} / \mathrm{m}^{3}$ (i.e. Sample SC-1), the value of $\theta_{S}$ however reduced, suggesting more presence of occluded air, possibly due to the more hydrophobic behavior of the exudation. At desaturation, SWRC of Sample SC-1 became noticeably steeper than the bare sample. This may be explained using the root decay hypothesis, previously put forward to explain the corresponding increase in saturated permeability. As roots became impoverished, and spaces were left around them, the pore size should become more uniformly distributed and the SWRC would be steeper. The air entry values, as presented in Figure12 and Table 2, nevertheless appeared to be relatively unchanged as root biomass increased.

\section{Effects of roots on permeability functions}

Figures 11 and 12 shows permeability functions of the ML and SC specimens with different root contents respectively. Again, these curves were obtained from the middle tensiometer which represented the average suction in the sample. The saturated permeability, $k_{s a t}$, obtained from the conventional test (as shown previously in Figure 6) was also plotted in the same graph as the $\mathrm{k}$-value at suction $0.1 \mathrm{kPa}$ for convenience. Interestingly, there is significant difference between the k-value at near saturated condition determined by IP test (referred herein as $k_{1 k P a}$ ) and $k_{s a t}$, determined by the conventional test. The values of $k_{1 k P a}$, are defined as the permeability at suction range between 0.1 and $1 \mathrm{kPa}$ in Figures 11 and 12, which correspond to degree of saturation between 90 and 100\%, hence being close to soaked condition. The difference between the values of $k_{1 k P a}$ and $k_{s a t}$ could be due to a combination of factors, i.e. the permeability dependency on positive pore pressure and effective stress (e.g. Leroueil and Hight 2013); the less accuracy of the permeability determined by IP test at small suction (Peters and Durner 2008); as well as the presence of air-bubbles and their dissolution with testing time (Snehota et al. 2015). 
Figure 12 shows that biomodality of permeability function, or the double s-curve, is evident in Sample SC-2, where $k_{s a t}$ was similar to $k_{l k P a}$. This trend was not observed for Samples SC-3 and SC-4 even though they were of similar root content. The reason for this is unclear but expected to be due to plant variation which could also cause significant change in permeability at small range of suction. It is speculated that the root content of SC-2, SC-3, and SC-4 was around the threshold at which root effect started to impede water flow. The effect of root may be abrupt, i.e. with a minor increase of root content, the water flow was blocked. This range of suction $(0.1$ to $1 \mathrm{kPa})$ corresponds to macro pore size range from 1.5 to $0.15 \mathrm{~mm}$ which was about the size of grass roots. Distribution of these macro pores would be affected by roots to a greater extent than other smaller size pores. For the smaller pore size, corresponding to higher suction of $30 \mathrm{kPa}$, the $\mathrm{k}$-function appeared to converge indicating less influence of roots on these void classes.

\section{Conclusion}

Grass roots can affect soil's hydraulic properties in a number of ways. Previous research showed that actively growing roots could reduce saturated permeability while decayed root would cause preferential flow path, increasing permeability. In this study, the effects of Vetiver grass (Chrysopogon zizanioides) on soil-water retention curves (SWRC), permeability $(\mathrm{k})$ function and saturated permeability, $k_{s a t}$, have been investigated on two soil types; low plasticity silt (ML) and clayey sand (SC), compacted at $80 \%$ standard Proctor density.

Grass roots have been shown to affect the hydraulic behavior of soils more significantly in the range of macro pore size greater than about $1.5 \mathrm{~mm}$, corresponding to suction less than $1 \mathrm{kPa}$. For ML soil, when the root biomass per soil volume were less than 6 $\mathrm{kg} / \mathrm{m}^{3}$, the saturated permeability increased, the air-entry suction reduced and the SWRC 
became steeper with increasing root contents, probably due to the formation of cracks due to wetting \& drying cycles during plant growing period. Nevertheless, roots appeared to reduce the saturated permeability and slightly increase the air-entry suction of ML soil, after reaching this threshold with root content of about $6.5 \mathrm{~kg} / \mathrm{m}^{3}$ as roots occupied the macropores and tended to suppress cracks and swelling. For SC soil for all root contents, only slight variation of the saturated permeability with root content can be observed for the upper bound on saturated permeability. However, the lower bound on saturated permeability appeared to decrease as root biomass increased. It has also been shown that for suction range beyond 30 $\mathrm{kPa}$, the influence of roots on permeability appeared to be less significant.

\section{Acknowledgements}

This research was financially supported by the Chaipattana Foundation and the Kasetsart University Research and Development Institute (KURDI). Their contributions are gratefully acknowledged.

\section{References}

ASTM. 2006. Standard test method for permeability of granular soils (constant head) (withdrawn 2015). ASTM standard D2434-68(2006). American Society for Testing and Materials, West Conshohocken, Pa. doi:10.1520/D2434-68R06.

ASTM. 2010. Standard test methods for measurement of hydraulic conductivity of saturated porous materials using a flexible wall permeameter. ASTM standard D5084-10 (2010). 
American Society for Testing and Materials, West Conshohocken, Pa. doi:10.1520/D5084-16A.

ADPC. 2006. Rapid assessment, flashflood and landslide disaster in the provinces of Uttaradit and Sukhothai, northern Thailand. Asian Disaster Preparedness Center. Bangkok, Thailand.

Albrecht, B. A., and Benson, C. H. 2001. Effect of desiccation on compacted natural clays. Journal of Geotechnical and Geoenvironmental Engineering, 127(1): 67-75. doi: 10.1061/(ASCE)1090-0241(2001)127:1(67).

Baecher, G.B., and Christian, J.T. 2003. Reliability and statistics in geotechnical engineering. John Wiley \& Sons Inc. USA.

Barley, K.P. 1954. Effects of root growth and decay on the permeability of a synthetic sandy loam. Soil Science, 78(3): 205-210.

Bengough, A.G. 2012. Water dynamics of the root zone: Rhizosphere biophysics and its control on soil hydrology. Vadose Zone Journal, 11(2): doi: 10.2136/vzj2011.0111.

Benson, C.H. 1993. Probability distributions for hydraulic conductivity of compacted soil liners. Journal of Geotechnical and Geoenvironmental Engineering, 119(3): 471-486.

Bo, M.W., Fabius, M., Arulrajah, A., and Horpibulsuk, S. 2015. Environmentally friendly slope stabilization using a soil nail and root system in Canada. In Ground Improvement Case Histories: Chemical, Electrokinetic, Thermal and Bioengineering Methods. Edited by Indraratna, B., Chu, J., and Rujikiatkamjorn, C. Butterworth-Heinemann. pp. 629654. doi: 10.1016/B978-0-08-100191-2.00021-6.

Böhm, W. 1979. Methods of studying root systems. Springer-Verlag Berlin Heidelberg.

Bodner, G., Scholl, P., and Kaul, H.-P. 2013. Field quantification of wetting-drying cycles to predict temporal changes of soil pore size distribution. Soil and Tillage Research, 133: 1-9. doi:10.1016/j.still.2013.05.006. 
Clewer, A. G., and Scarisbrick, D. H. 2001. Practical statistics and experimental design for plant and crop science. John Wiley \& Sons, Ltd.

Coppin, N. J., Barker, D. L., and Richards, I. 1990. Use of vegetation in civil engineering. Butterworths, London.

Delis P.C., Effendi H., Krisanti M., and Hariyadi S. 2015. Treatment of aquaculture wastewater using Vetiveria zizanioides (Liliopsida, Poaceae). AACL Bioflux, 8(4): 616-625.

Ghezzehei, T.A., and Albalasmeh, A.A. 2015. Spatial distribution of rhizodeposits provides built-in water potential gradient in the rhizosphere. Ecological Modelling, 298: 53-63. doi: 10.1016/j.ecolmodel.2014.10.028.

Goldsmith, W., Silva, M., and Fischenich, C. 2001. Determining optimal degree of soil compaction for balancing mechanical stability and plant growth capacity. ERDC TNEMRRP-SR-26), U.S. Army Engineer Research and Development Center,Vicksburg, MS.

Goldsmith, W., Gray, D.H., and McCullah, J. 2014. Bioengineering Case Studies Sustainable Stream Bank and Slope Stabilization, Springer.

Gray, D.H. and Sotir, R.B. 1996. Biotechnical and Soil Bioengineering Slope Stabilization: A Practical Guide for Erosion Control, John Wiley \& Sons.

Gray, D.H. 2002. Optimizing Soil Compaction and Other Strategies: Balancing engineering requirements and plant-growth needs in slope protection and erosion control work. Erosion Control, Official Journal of the international erosion control association, September-October, 2002.

Grayston, S.J., Vaughan, D., and Jones, D. 1997. Rhizosphere carbon flow in trees, in comparison with annual plants: the importance of root exudation and its impact on microbial activity and nutrient availability. Applied Soil Ecology, 5(1): 29-56. 
Greenway, D.R. 1987. Vegetation and slope stability. In Slope stability. Edited by M.F.Anderson and K.S. Richard. Wiley, New York.

Grimshaw, R.G. 1994. Vetiver grass - its use for slope and structure stabilization under tropical and semitropical conditions. In Vegetation and slopes. Edited by D.H. Barker. Institution of Civil Engineers, London. pp. 26-35. doi:10.1680/vasspae.20313.0003.

Hamilton, J. M., Daniel, D. E., and Olson, R. E. 1981. Measurement of hydraulic conductivity of partially saturated soils. In Permeability and Groundwater Contaminant Transport. Edited by T. F. Zimmie and C. O. Riggs. ASTM Special Technical Publication 746, American Society for Testing and Materials, Philadelphia, PA, pp. $182-196$.

Hengchaovanich, D. 1998. Vetiver grass for slope stabilization and erosion control, with particular reference to engineering applications. Technical Bulletin No. 1998/2. Pacific Rim Vetiver Network. Office of the Royal Development Project Board, Bangkok, Thailand.

Hillel, D. 1998. Environmental soil physics. Academic Press

HilleRisLambers, R., Rietkerk, M., Bosch, Fvd., Prins, H.H.T., and Kroon, Hd. 2001. Vegetation Pattern Formation in Semi-Arid Grazing Systems. Ecology 82(1): 50-61.

Huat, B.B.K., Ali, F. Hj., and Mariappan, S. 2005. Effect of surface cover on water infiltration rate and stability of cut slope in residual soils. Electronic Journal of Geotechnical Engineering, 10G.

Huat, B.B.K., Ali, F.Hj., and Low, T.H. 2006. Water infiltration characteristics of unsaturated soil slope and its effect on suction and stability. Geotechnical and Geological Engineering, 24(5): 1293-1306. doi: 10.1007/s10706-005-1881-8. 
Indraratna, B., Fatahi, B., and Khabbaz, H. 2006. Numerical analysis of matric suction effects of tree roots. In Proceedings of the Institution of Civil Engineers: Geotechnical Engineering, 159(2), April 2006, pp.77-90. doi:10.1680/geng.2006.159.2.77.

Jotisankasa, A. 2001. Evaluating the parameters that control the stability of municipal solid waste landfills. M.Sc. thesis, Department of Civil and Environmental Engineering, Imperial College of Science, Technology and Medicine, London.

Jotisankasa, A., Porlila, W., Soralump, S., and Mairiang, W. 2007. Development of a low cost miniature tensiometer and its applications. In Proceedings of the 3rd Asian Conference on Unsaturated Soils (Unsat-Asia 2007), Nanjing, China, Science Press, pp. $475-480$.

Jotisankasa, A. and Tapparnich, J. 2010. Shear and soil-water retention behaviour of a variably saturated residual soil and its implication on slope stability. In Unsaturated Soils. Vol. 2, Proceedings of the 5th International conference on unsaturated soils, Barcelona, Spain, 6-8 September 2010, CRC Press, pp. 1249-1254.

Jotisankasa, A., Vadhanabhuti, B, Lousuphap, K., and Sawangsuriya, A. 2011. Mechanisms of longitudinal cracks along highway shoulder in central Thailand. In Proceedings of the $5^{\text {th }}$ Asia-Pacific Conference on Unsaturated Soils, Pattaya, Thailand, pp. 699-705.

Jotisankasa, A., Mairaing, W. and Tansamrit, S. 2014. Infiltration and stability of soil slope with vetiver grass subjected to rainfall from numerical modeling. In Proceedings of the $6^{\text {th }}$ International conference on unsaturated soils, UNSAT 2014, Unsaturated Soils: Research \& Applications Sydney Australia 2-4 July 2014, pp 1241-1247.

Jotisankasa, A., Sirirattanachat, T., Rattana-areekul, C., Mahannopkul, K. and Sopharat, J. 2015a. Engineering characterization of Vetiver system for shallow slope stabilization. In Proceedings of the $6^{\text {th }}$ International Conference on Vetiver (ICV-6), Danang, Vietnam, 5-8 $\quad$ May, 2015. Available from 
http://www.vetiver.org/ICV6_PROC/ICV6_papers-index.htm (accessed 14 November 2016)

Jotisankasa, A., Mahannopkul, K., Teerachaikulpanich, N., Miyashita, T., and Tada, Y. 2015b. Investigation of high-seepage zones in slopes using the Groundwater Aeration Sound (GAS) survey technique in Thailand. In Proceedings of the 15th Asian Regional Conference on Soil Mechanics and Geotechnical Engineering, Fukuoka, THA03.

Jotisankasa, A., and Taworn, D. 2016. Direct Shear Testing of Clayey Sand Reinforced with Live Stake. Geotechnical Testing Journal, 39(4): 608-623. doi: 10.1520/GTJ20150217. Krisdani, H., Rahardjo, H., and Leong, E.C. 2009. Use of Instantaneous Profile and Statistical Methods to Determine Permeability Functions of Unsaturated Soils. Canadian Geotechnical Journal, 46(7): 869-874. doi: 10.1139/T09-027.

Kroener, E., Zarebanadkouki, M., Kaestner, A., and Carminati, A. 2014. Nonequilibrium water dynamics in the rhizosphere: How mucilage affects water flow in soils. Water Resources Research, 50. doi: 10.1002/2013WR014756.

Landva, A.O. and Clark, J.I. 1990. Geotechnics of waste fill. Geotechnics of waste fillTheory and Practice, ASTM STP 1070, ASTM, Philadelphia, USA, pp. 86-103.

Leroueil, S. and Hight, D.W. 2013. Compacted soils: From physics to hydraulic and mechanical behaviour. In Advances in Unsaturated Soils - Proceedings of the $1^{\text {st }}$ PanAmerican Conference on Unsaturated Soils, PanAmUNSAT 2013, Cartagena de Indias, Colombia, 20 February 2013, pp. 41-59.

Leung, F.T.Y., Yan, W.M., Hau, B.C.H., and Tham, L.G. 2015a. Root systems of native shrubs and trees in Hong Kong and their effects on enhancing slope stability. Catena. 125:102-110. doi: 10.1016/j.catena.2014.10.018. 
Leung, A.K, Garg, A., and Ng, C.W.W. 2015b. Effects of plant roots on soil-water retention and induced suction in vegetated soil. Engineering Geology, 193: 183-197. doi: 10.1016/j.enggeo.2015.04.017.

Leung, A. K., Garg, A., Coo, J. L., Ng, C. W. W., and Hau, B. C. H. 2015c. Effects of the roots of Cynodon dactylon and Schefflera heptaphylla on water infiltration rate and soil hydraulic conductivity. Hydrological Processes, 29(15): 3342-3354. doi: 10.1002/hyp.10452.

Li, Y., and Ghodrati, M. 1994. Preferential transport of nitrate through soil columns containing root channels. Soil Science Society of America Journal, 58(3): 653-659.

Li, J.H., Li, L., Chen, R., and Li, D.Q. 2016. Cracking and vertical preferential flow through landfill clay liners. Engineering Geology, 206: 33-41. doi:10.1016/j.enggeo.2016.03.006.

Lu, N., Alsherif, N., Wayllace, A., and Godt, J. 2014. Closing the Loop of the Soil Water Retention Curve. Journal of Geotechnical and Geoenvironmental Engineering, 141(1): 1. doi:10.1061/(ASCE)GT.1943-5606.0001225.

Ma, R., Cai, C., Li, Z., Wang, J., Xiao, T., Peng, G., and Yang, W. 2015. Evaluation of soil aggregate microstructure and stability under wetting and drying cycles in two Ultisols using synchrotron-based X-ray micro-computed tomography. Soil and Tillage Research, 149: 1-11. doi:10.1016/j.still.2014.12.016.

Mairaing, W., Jotisankasa, A., and Soralump, S. 2012. Some applications of unsaturated soil mechanics in Thailand: an appropriate technology approach. Geotechnical Engineering. 43(1): 1-11.

Ng, C.W.W., and Leung, A.K. 2012. In-situ and laboratory investigations of stress-dependent permeability function and SDSWCC from an unsaturated soil slope. Geotechnical Engineering, 43(1): 26-39. 
Ng, C.W.W., Leung, A.K., Kamchoom, V., and Garg, A. 2014. A novel root system for simulating transpiration-induced soil suction in centrifuge. Geotechnical Testing Journal, 37(5): 1-15. doi:10.1520/GTJ20130116.

Nilaweera, N.S., and Nutalaya, P. 1999. Role of tree roots in slope stabilization. Bulletin of Engineering Geology and the Environment, 57(4): 337-342.

Oweis, I.S., and Khera, R.P. 1998. Geotechnology of waste management. Butterworth \& Co.

Peng, X., Horn, R., and Smucker, A. 2007. Pore shrinkage dependency of inorganic and organic soils on wetting and drying cycles. Soil Science Society of America Journal, 71(4): 1095-1103. doi: 10.2136/sssaj2006.0156.

Peters, A., and Durner, W. 2008. Simplified evaporation method for determining soil hydraulic properties. Journal of Hydrology, 356(1-2): 147-162. doi: 10.1016/j.jhydrol.2008.04.016.

Rachman, A., Anderson, S.H., Gantzer, C.J., and Alberts, E.E. 2004. Soil Hydraulic Properties Influenced by Stiff Stemmed Grass Hedge Systems. Soil Science Society of America Journal, 68(4): 1386-1393.

Rahimi, A., Rahardjo, H., and Leong, E.C. 2010. Effect of Hydraulic Properties of Soil on Rainfall-Induced Slope Failure. Engineering Geology, 114(3-4): 135 - 143. doi: 10.1016/j.enggeo.2010.04.010.

Rahardjo, H., Satyanaga, A., Leong, E.C., Santoso, V.A., and Ng, Y.S. 2014. Performance of an Instrumented Slope Covered with Shrubs and Deep Rooted Grass. Soils and Foundations, 54(3): 417-425. doi: 10.1016/j.sandf.2014.04.010.

Raharjo, S., Suprihatin, S., Indrasti, N.S., and Riani, E. 2015. Phytoremediation of vaname shrimp (Litopenaeus vannamei) waste water using vetiver grass system (Chrysopogon zizanioides, L) in flow water surface-constructed wetland. AACL Bioflux, 8(5): 796804. 
Rasse, D.P., Smucker, A.J.M., and Santos, D. 2000. Alfalfa root and shoot mulching effects on soil hydraulic properties and aggregation. Soil Science Society of America Journal, 64(2): 725-731.

Rewald, B., and Ephrath, J.E. 2013. Minirhizotron techniques. Chapter 42. In Plant roots: The hidden half. Edited by Eshel, A. and Beeckman, T. CRC Press, New York, USA. pp. 148.

Roongtanakiat, N., Nirunrach, T., Chanyotha, S., and Hengchaovanich, D. 2003. Uptake of Heavy Metals in Landfill Leachate by Vetiver Grass" Kasetsart Journal (Natural Science), 37: $168-175$.

Scanlan, C.A., and Hinz, C. 2010. Insight into the processes and effects of root induced changes to soil hydraulic properties. In Proceedings of the 19th World Congress of Soil Science, Soil Solutions for a Changing World, Brisbane, Australia, 1-6 August 2010, pp. 41-44. Published on DVD.

Snehota, M., Jelinkova, V., Sobotkova, M., Sacha, J., Vontobel, P., and Hovind, J. 2015. Water and entrapped air redistribution in heterogeneous sand sample: Quantitative neutron imaging of the process", Water Resource Research, 51(2): 1359-1371, doi:10.1002/2014WR015432.

Styczen, M.E., and Morgan, R.P.C. 1995. Engineering properties of vegetation. In Slope stabilization and erosion control, A bioengineering approach. Edited by Morgan, R.P.C and Rickson, R.J. Chapman and Hall. pp. 5-58.

Tansamrit, S., and Suanburi, D. 2012. Landslide risk status of road high cutting sandstone slope by $2 \mathrm{~d}$ resistivity imaging and seismic refraction technique. In Proceedings of the $6^{\text {th }}$ International conference on applied geophysics, Kanchanaburi, Thailand. 15-17 November 2012. 
Tian, Y., Liu, C.H., Smucker, A.J.M., Li, H., and Zhang, W. 2015. Plant root exudates decrease mobility of smectite colloids in porous media in contrast to humic acid. Soil Science Society of America Journal, 79(2): 467-475. doi: 10.2136/sssaj2014.10.0412.

Traoré, O., Groleau-Renaud, V., Plantureux, S., Tubeileh, A., and Boeuf-Tremblay, V. 2000. Effect of root mucilage and modelled root exudates on soil structure. European Journal of Soil Science, 51(4): 575-581. doi: 10.1046/j.1365-2389.2000.00348.x.

Truong, P., Van, T.T. and Pinners, E. 2008. The vetiver system for slope stabilization, an Engineer's handbook. The Vetiver Network International.

Wu, T.H., Mckinnel, W.P., and Swanston, D.N. 1979. Strength of tree roots and landslides on Prince of Wales Island, Alaska. Canadian Geotechnical Journal, 16(1): 19-33.

\section{Figure Captions}

Figure 1 Instantaneous Profile (IP) drying test

Figure 2 Typical test result of drying IP test (Sample ML-3, root biomass per soil volume = $\left.5.59 \mathrm{~kg} / \mathrm{m}^{3}\right)$

Figure 3 Drying SWRCs from IP drying tests and point-wise SWRC tests, on samples with no root (a) low plasticity Silty soil, ML, and (b) clayey Sand, SC

Figure 4 Example of a specimen and exposed roots

Figure 5 Phase diagrams for soil containing roots

Figure 6 Variation of saturated permeability with root content of (a) Low plasticity Silt, and (b) clayey Sand (Trendlines and error bar correspond to $80 \%$ confidence interval)

Figure 7 Soil-water retention curves of silt samples (ML) with and without roots (numbers in brackets indicate root biomass per soil volume)

Figure 8 Variation of porosity soaked volumetric water content and air-entry suction with root biomass for low plasticity Silt (ML) 
Figure 9 Soil-water retention curves of clayey sand (SC) with and without roots (numbers in brackets indicate root biomass per soil volume)

Figure 10 Variation of porosity, soaked volumetric water content and air-entry suction with root biomass for clayey sand (SC)

Figure 11 Permeability functions of low plasticity Silt (ML) with and without roots (numbers in brackets indicate root biomass per soil volume)

Figure 12 Permeability functions of clayey Sand (SC) with and without roots (numbers in brackets indicate root biomass per soil volume) 
Upward flux measured as

Trimmed grass total mass change rate

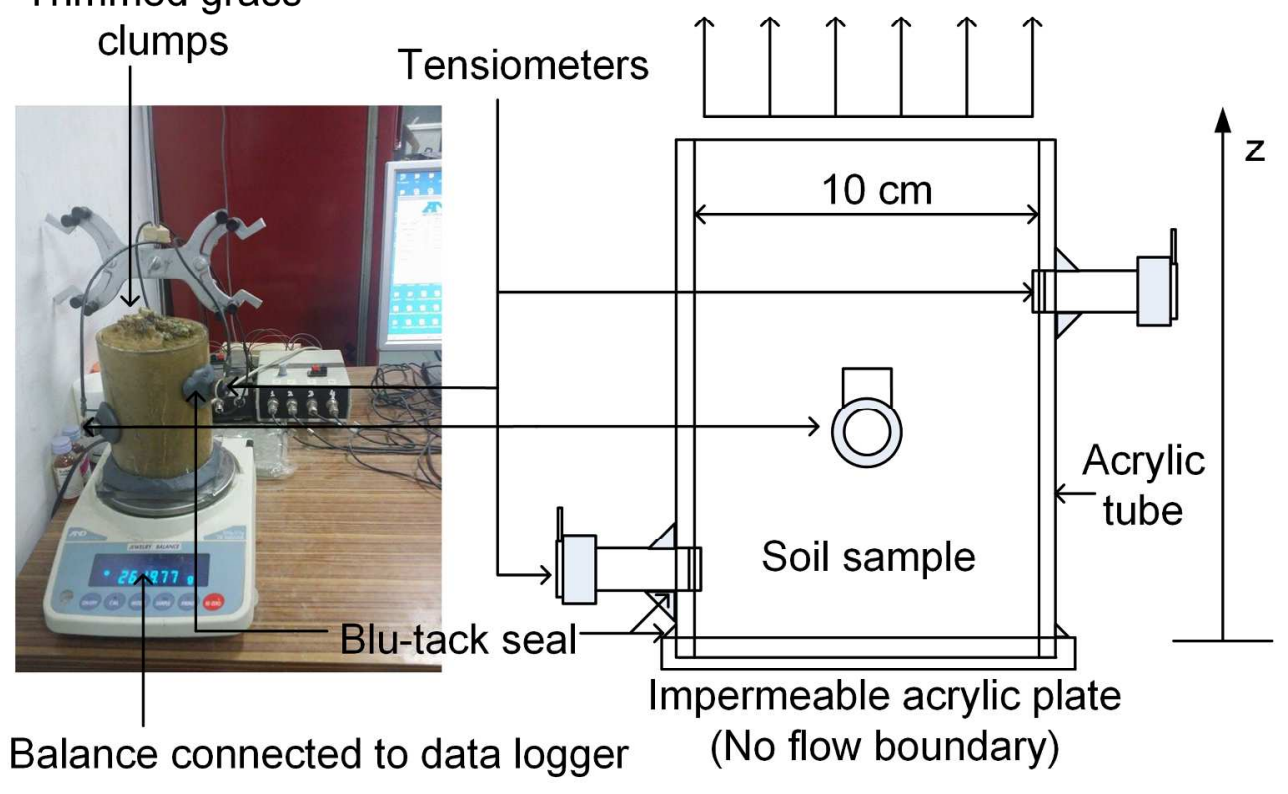

Figure 1 Instantaneous Profile (IP) drying test $197 \times 138 \mathrm{~mm}(300 \times 300$ DPI $)$ 

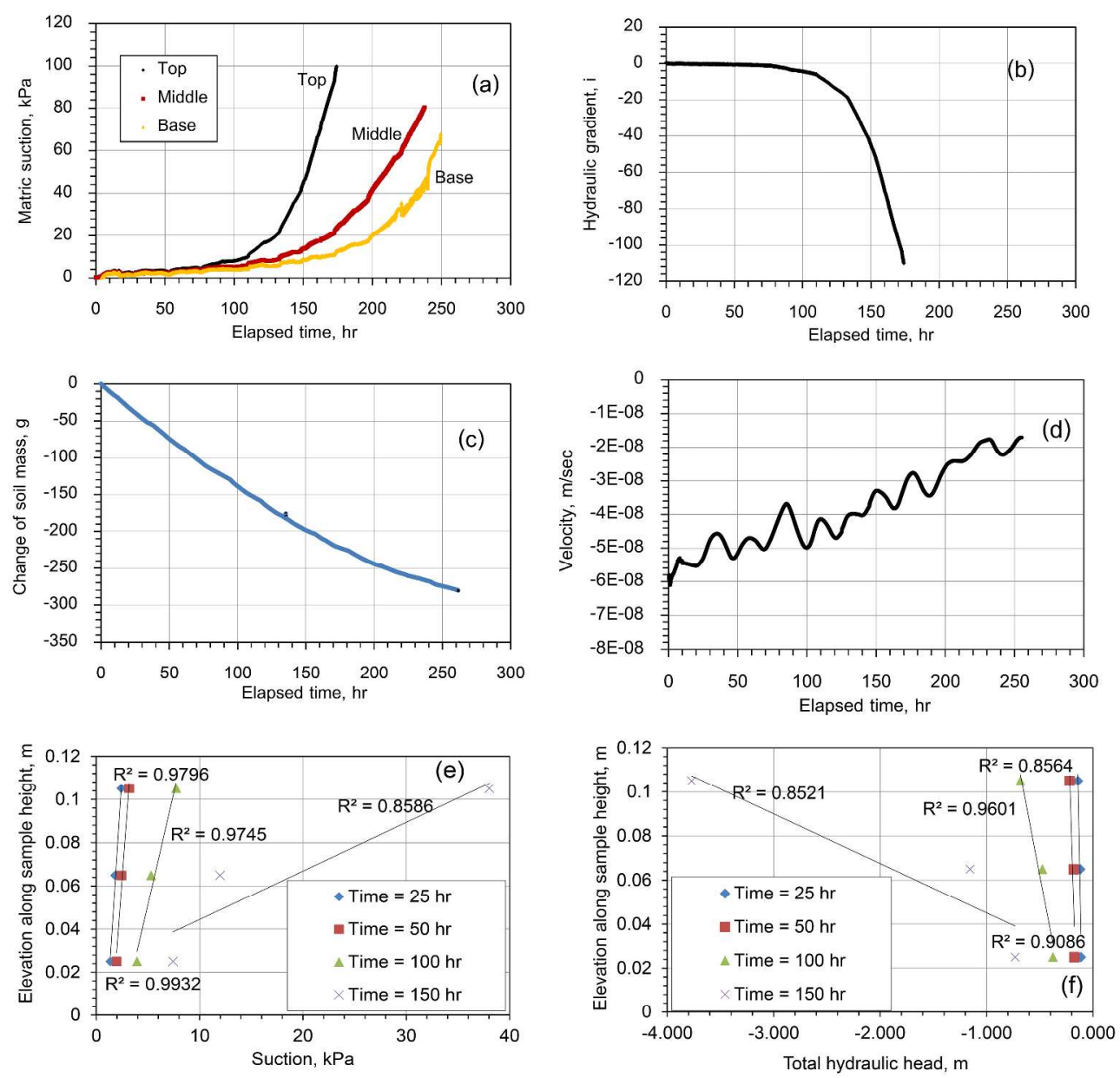

Figure 2 Typical test result of drying IP test (Sample ML-3, root biomass per soil volume $=5.59 \mathrm{~kg} / \mathrm{m} 3$ ) $405 \times 395 \mathrm{~mm}(300 \times 300$ DPI $)$ 

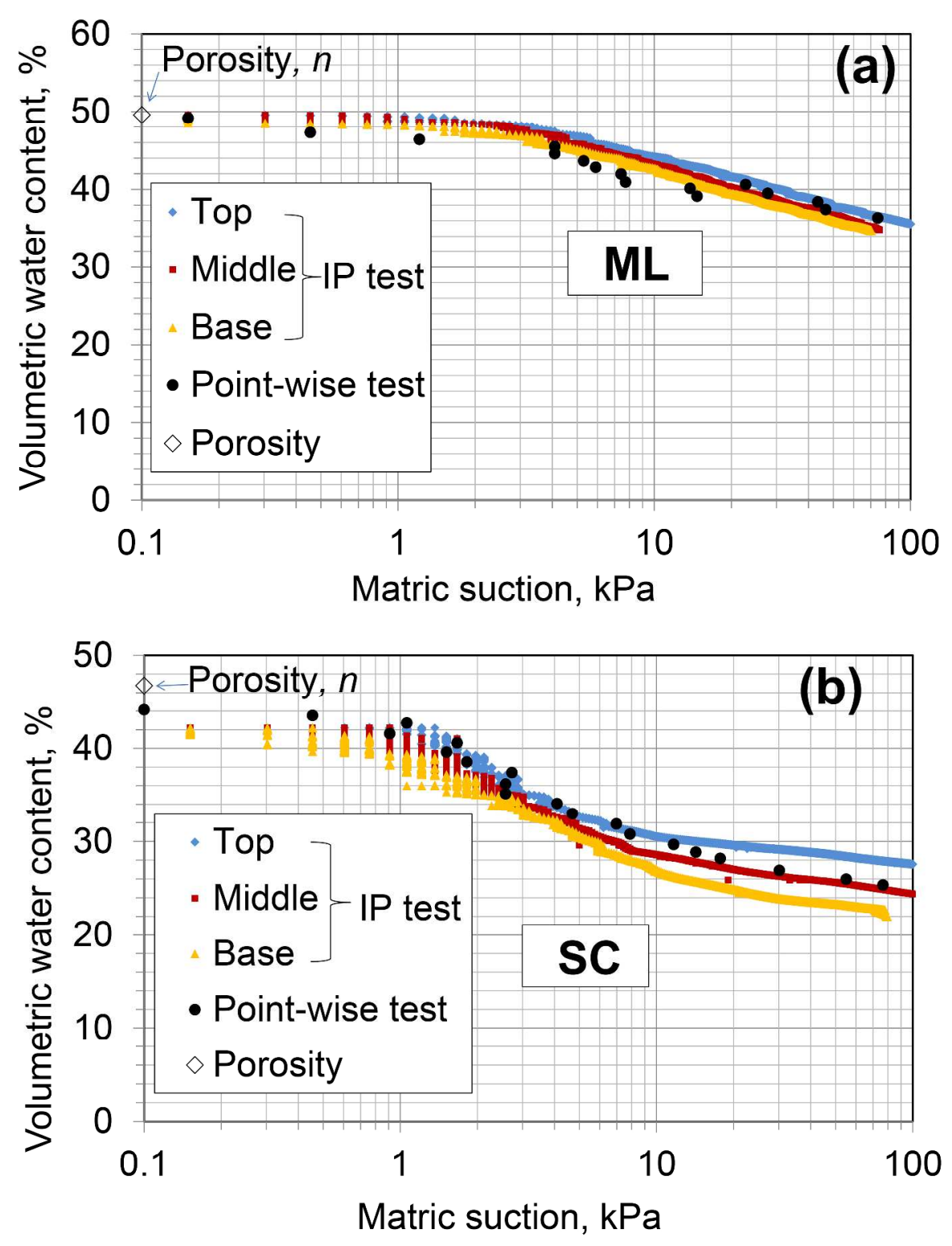

Figure 3 Drying SWRCs from IP drying tests and point-wise SWRC tests, on samples with no root (a) low plasticity Silty soil, ML, and (b) clayey Sand, SC

$296 \times 378 \mathrm{~mm}(300 \times 300 \mathrm{DPI})$ 

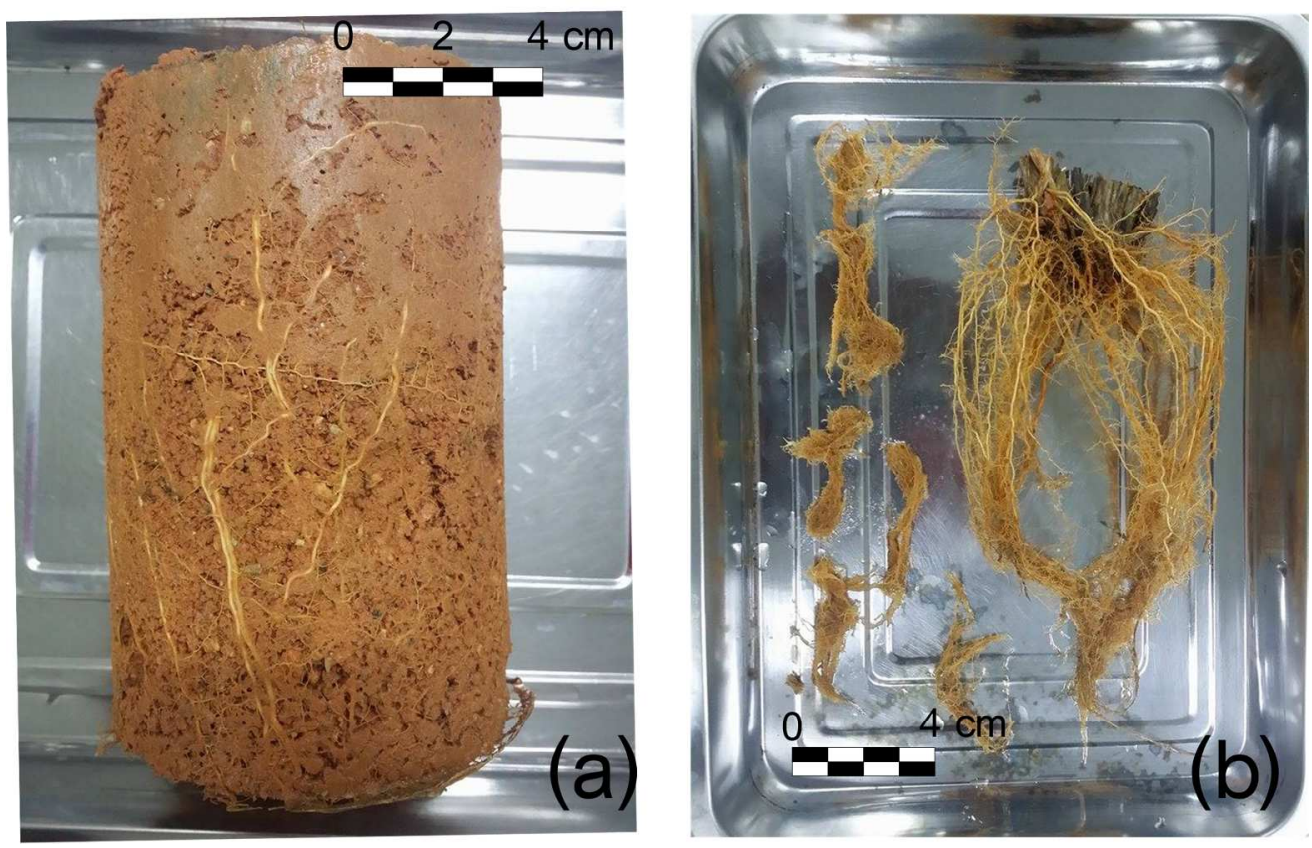

Figure 4 Example of a specimen and exposed roots $182 \times 120 \mathrm{~mm}(300 \times 300$ DPI) 


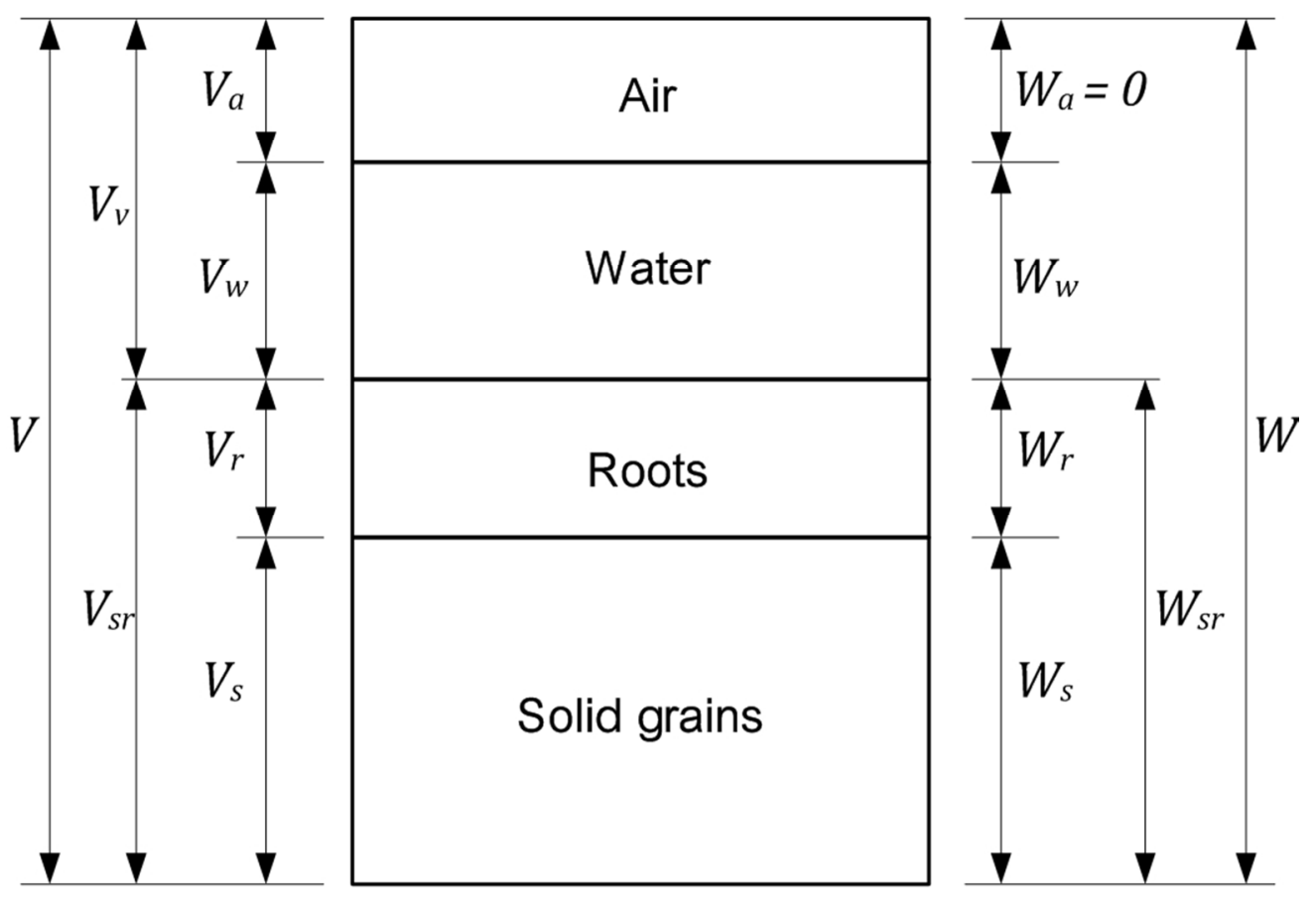

Figure 5 Phase diagrams for soil containing roots $89 \times 60 \mathrm{~mm}(300 \times 300 \mathrm{DPI})$ 

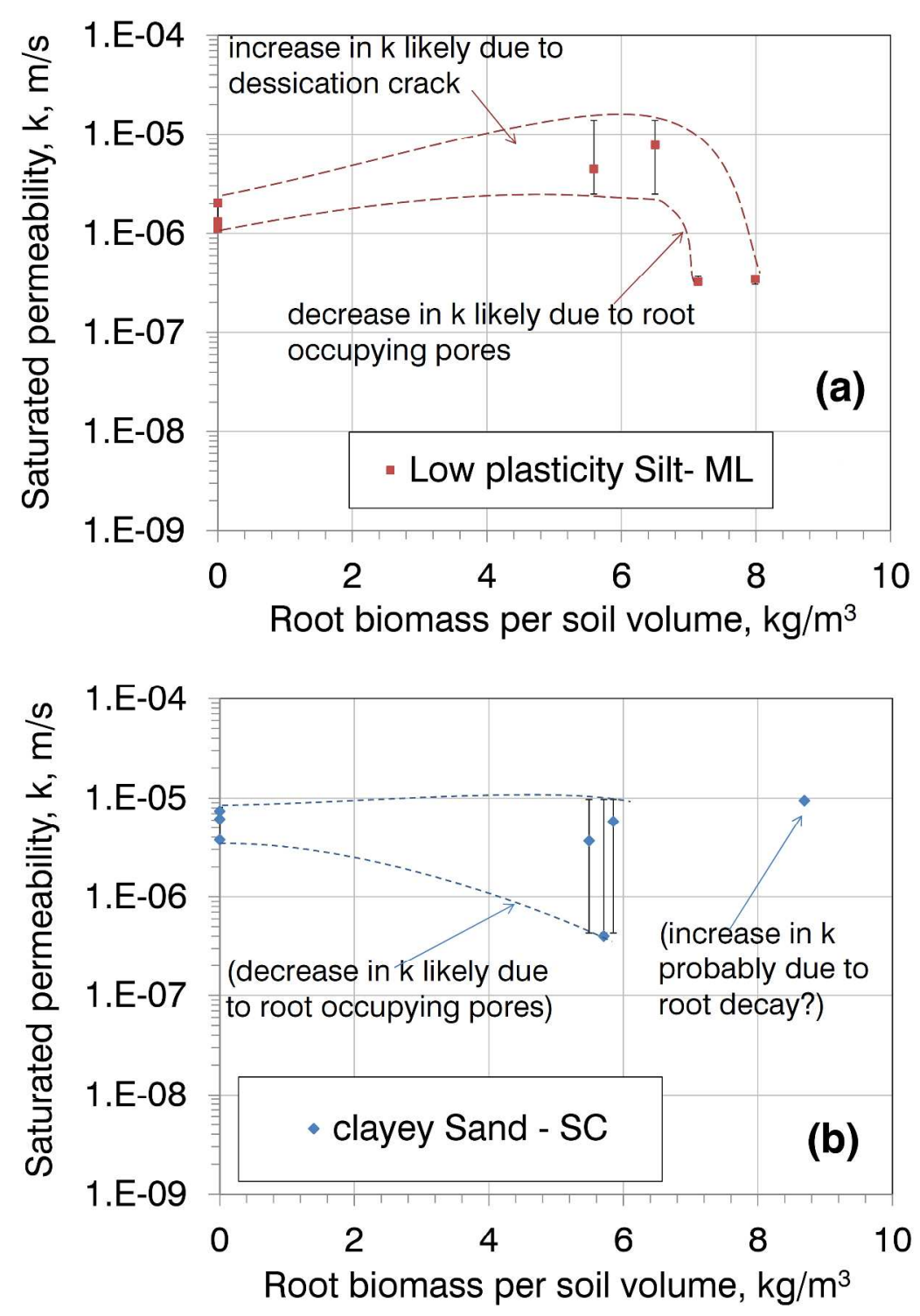

Figure 6 Variation of saturated permeability with root content of (a) Low plasticity Silt, and (b) clayey Sand (Trendlines and error bar correspond to $80 \%$ confidence interval)

$255 \times 355 \mathrm{~mm}(300 \times 300 \mathrm{DPI})$ 


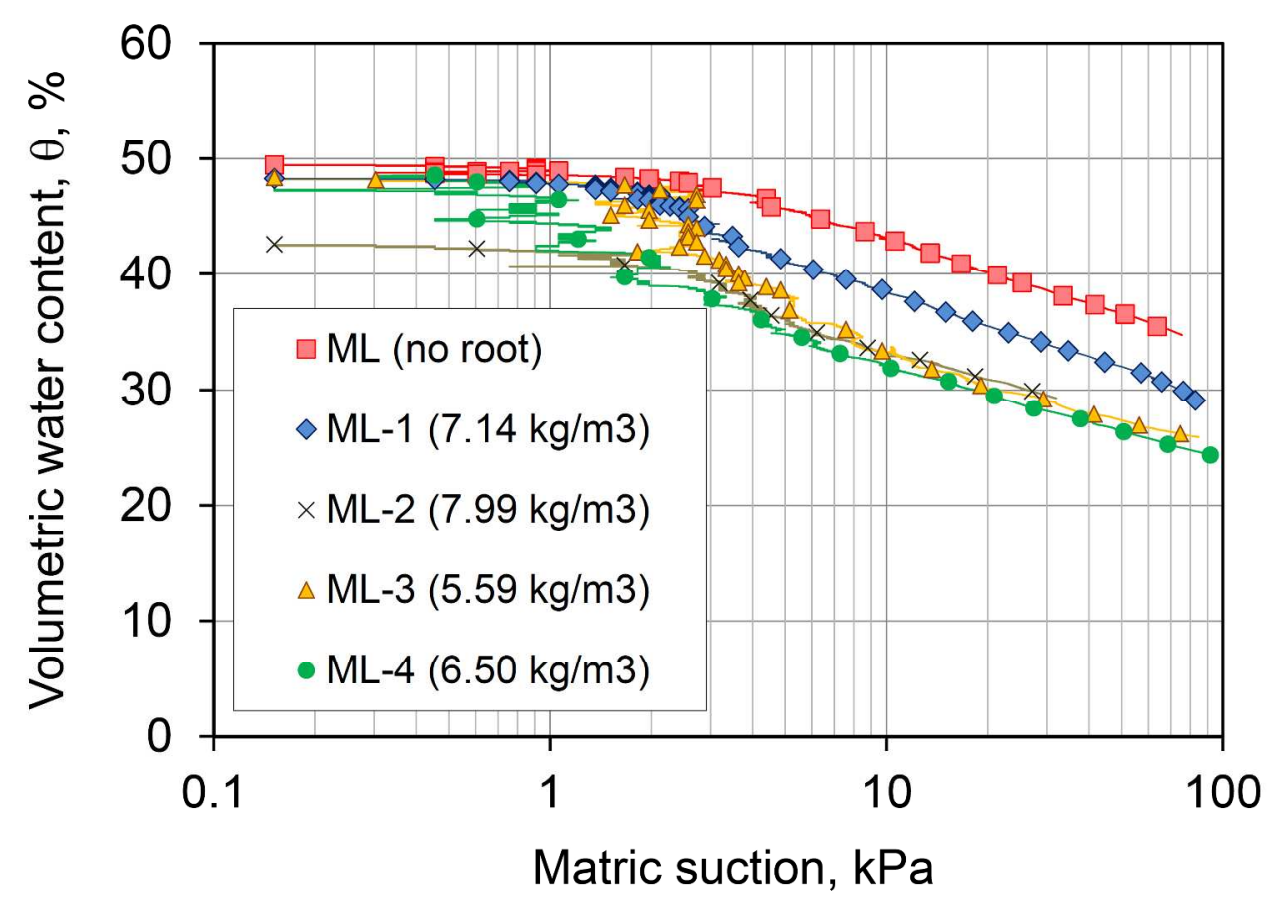

Figure 7 Soil-water retention curves of silt samples (ML) with and without roots (numbers in brackets indicate root biomass per soil volume)

$254 \times 178 \mathrm{~mm}(300 \times 300 \mathrm{DPI})$ 


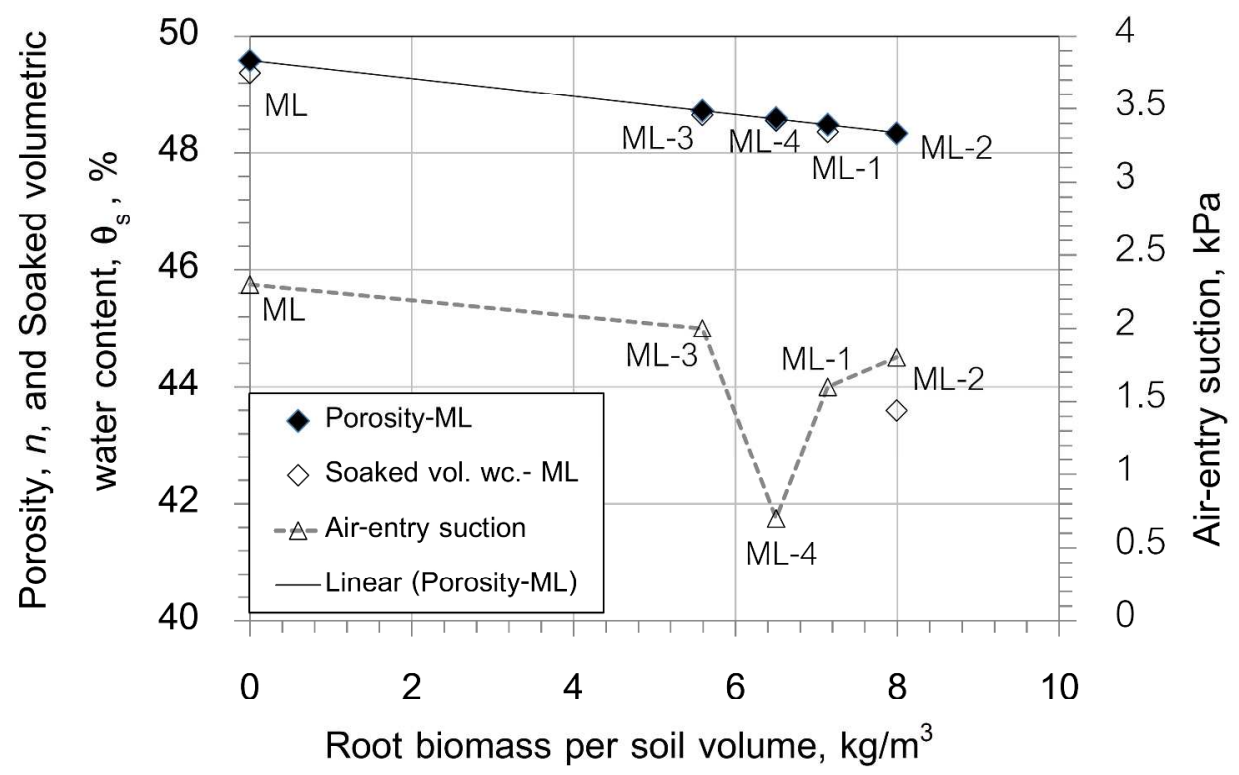

Figure 8 Variation of porosity soaked volumetric water content and air-entry suction with root biomass for low plasticity Silt (ML)

$287 \times 186 \mathrm{~mm}$ ( $300 \times 300$ DPI) 


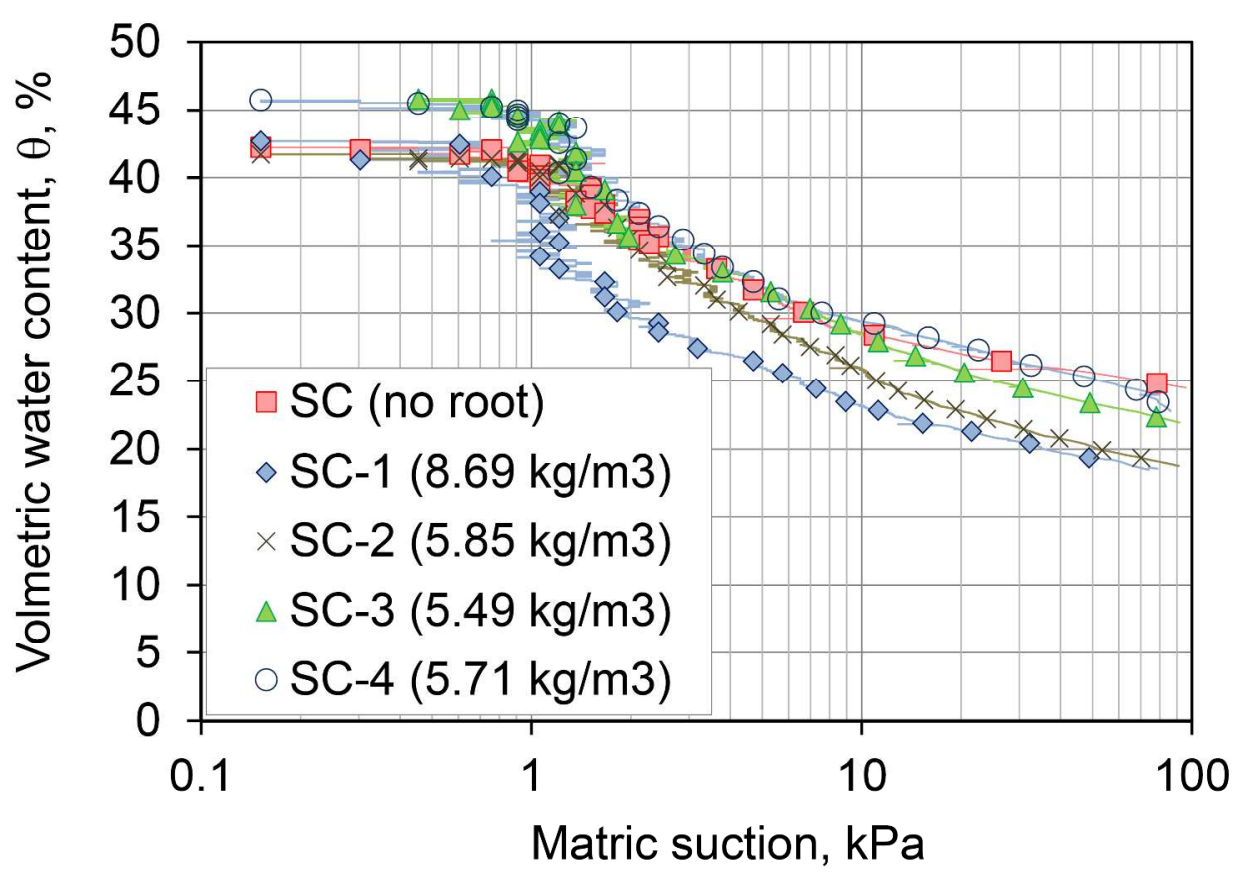

Figure 9 Soil-water retention curves of clayey sand (SC) with and without roots (numbers in brackets indicate root biomass per soil volume)

$$
259 \times 182 \mathrm{~mm}(300 \times 300 \text { DPI) }
$$




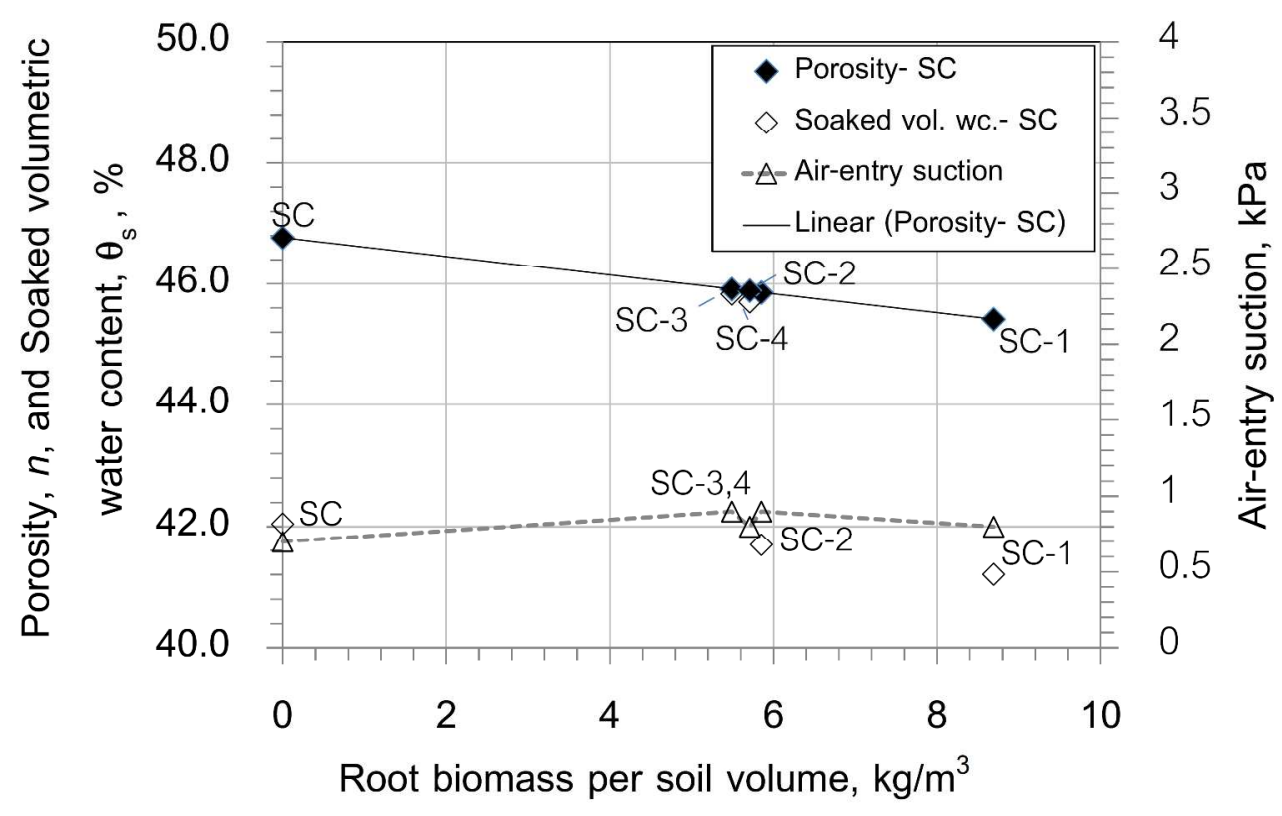

Figure 10 Variation of porosity, soaked volumetric water content and air-entry suction with root biomass for clayey sand (SC)

$277 \times 173 \mathrm{~mm}(300 \times 300$ DPI $)$ 


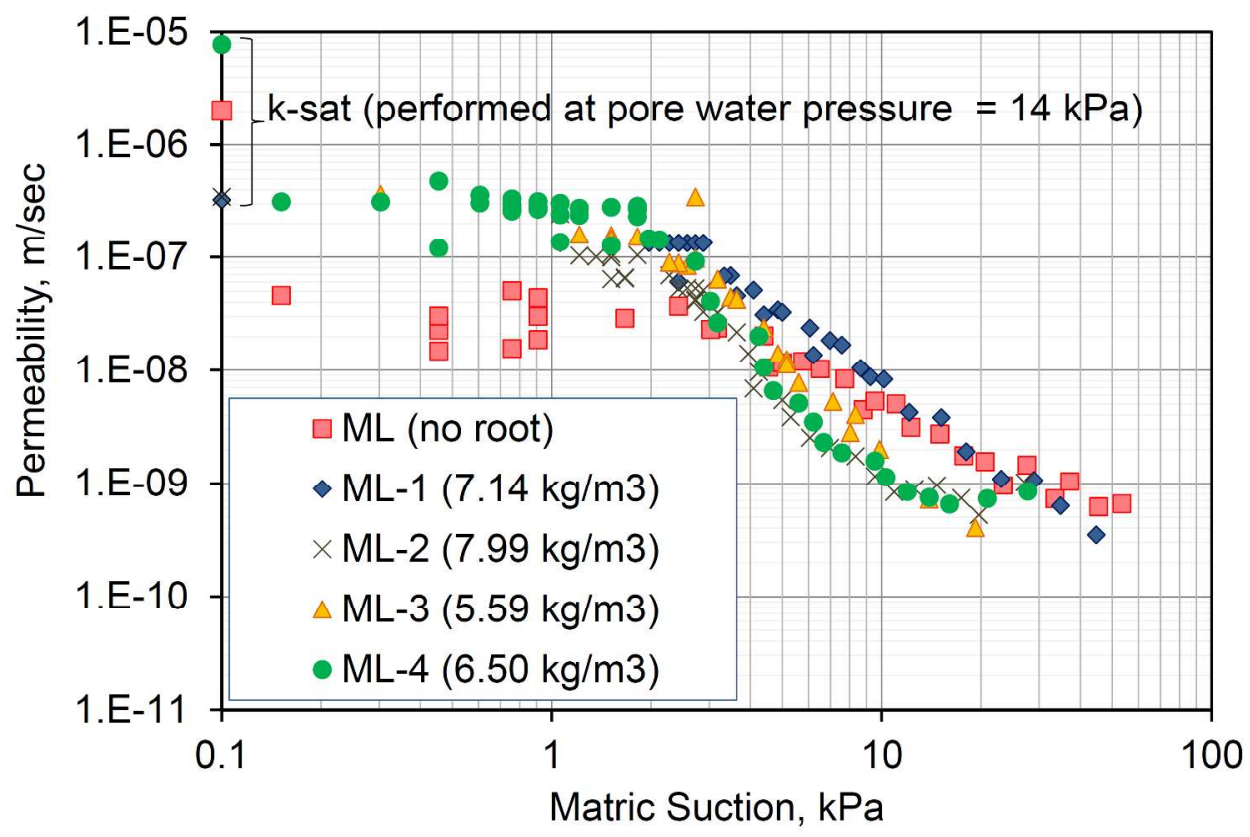

Figure 11 Permeability functions of low plasticity Silt (ML) with and without roots (numbers in brackets indicate root biomass per soil volume)

$$
259 \times 171 \mathrm{~mm}(300 \times 300 \mathrm{DPI})
$$




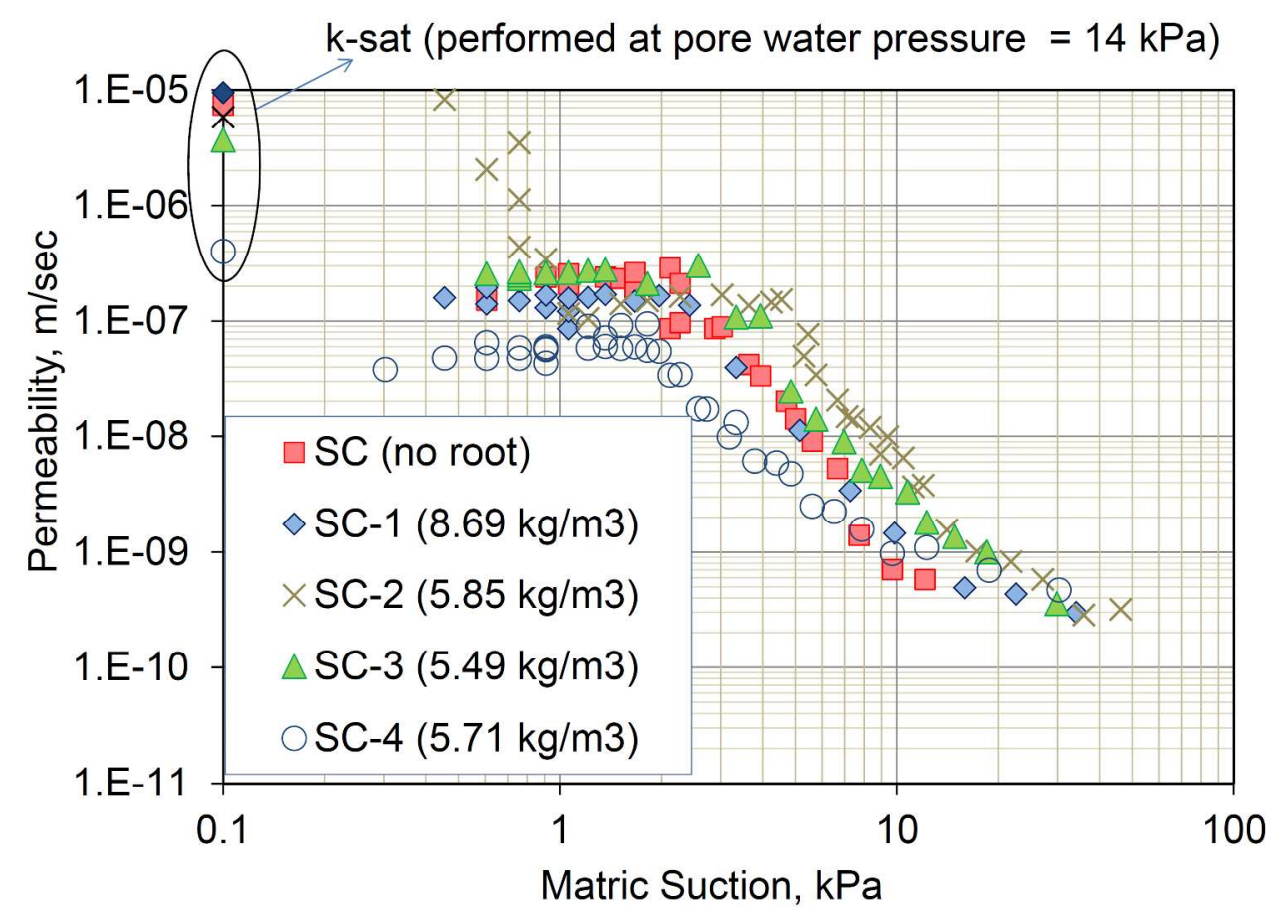

Figure 12 Permeability functions of clayey Sand (SC) with and without roots (numbers in brackets indicate root biomass per soil volume)

$253 \times 180 \mathrm{~mm}(300 \times 300 \mathrm{DPI})$ 
Table 1 Basic Soil Properties

\begin{tabular}{|c|c|c|c|}
\hline \multirow{2}{*}{ Test } & \multirow{2}{*}{ Test standard/Method } & \multicolumn{2}{|c|}{ Material } \\
\hline & & ML & $\mathrm{SC}$ \\
\hline Grain size distribution & \multirow{5}{*}{$\begin{array}{l}\text { ASTM D422-63 } \\
\text { ASTM D1140 }\end{array}$} & & \\
\hline Gravel $\leq 75 \mathrm{~mm}, \%$ & & 0 & 31.4 \\
\hline Sand $\leq 4.75 \mathrm{~mm}, \%$ & & 20.2 & 45.7 \\
\hline Silt $\leq 75 \mu \mathrm{m}, \%$ & & 51.8 & 15.4 \\
\hline Clay $\leq 2 \mu \mathrm{m}, \%$ & & 28.0 & 7.5 \\
\hline Specific gravity, $\mathrm{G}_{\mathrm{s}}$ & ASTM D854-02 & 2.65 & 2.69 \\
\hline \multicolumn{3}{|l|}{ Atterberg's Limits } & \\
\hline Liquid limit, LL, \% & & 39.3 & 31.2 \\
\hline Plastic limit, PL, \% & & 29.4 & 19.4 \\
\hline Plasticity index, PI, \% & & 9.9 & 11.8 \\
\hline $\begin{array}{l}\text { Soil nutrients } \\
\text { Organic content, \% }\end{array}$ & Wet oxidation & 1.95 (medium) & 0.69 (very low) \\
\hline $\mathrm{pH}$ & $\begin{array}{c}\mathrm{pH} \text { meter } \\
\text { (Soil:Water, } 1: 1)\end{array}$ & 6 (highly acidic) & 5 (highly acidic) \\
\hline $\mathrm{P}$, phosphorous, $\mathrm{mg} / \mathrm{kg}$ & Bray II (modified) & 17 (medium) & 3 (low) \\
\hline $\mathrm{K}$, potassium, $\mathrm{mg} / \mathrm{kg}$ & & 107 (high) & 64 (low) \\
\hline $\mathrm{Ca}$, calcium, $\mathrm{mg} / \mathrm{kg}$ & Atomic Absorption & 1509 (high) & 427 (medium) \\
\hline $\mathrm{Mg}$, magnesium, $\mathrm{mg} / \mathrm{kg}$ & & 216 (high) & 69 (medium) \\
\hline Standard Proctor compaction test & & & \\
\hline Maximum dry density, $\mathrm{kN} / \mathrm{m}^{3}$ & ASTM D698 - 12e 2 & 16.4 & 17.6 \\
\hline Optimum water content, $\%$ & & 18.9 & 15.4 \\
\hline $\begin{array}{l}\text { As-compacted dry density, } \\
\mathrm{kN} / \mathrm{m}^{3}\end{array}$ & ASTM D698 - 12e2 & 13.1 & 14.0 \\
\hline
\end{tabular}


Table 2 Description of tests and their results

\begin{tabular}{|c|c|c|c|c|c|c|}
\hline Soil type & Test no. & $\begin{array}{l}\text { Age of } \\
\text { plant, } \\
\text { days }\end{array}$ & $\begin{array}{l}\text { Root biomass per } \\
\text { unit volume of } \\
\text { soil, } \mathrm{kg} / \mathrm{m}^{3}\end{array}$ & $\begin{array}{c}\text { Saturated } \\
\text { permeability, } \\
\mathrm{m} / \mathrm{s}\end{array}$ & $\begin{array}{l}\text { Air-entry } \\
\text { suction, } \\
\qquad \mathrm{kPa}\end{array}$ & $\begin{array}{l}\text { IP test } \\
\text { duration, } \\
\text { days }\end{array}$ \\
\hline \multirow{7}{*}{$\begin{array}{l}\text { Low- } \\
\text { Plasticity } \\
\text { Silt, ML }\end{array}$} & ML-a & NA & 0 & $2.02 \mathrm{E}-06$ & 2.3 & 12 \\
\hline & ML-b & NA & 0 & $1.32 \mathrm{E}-06$ & - & - \\
\hline & ML-c & NA & 0 & $1.12 \mathrm{E}-06$ & - & - \\
\hline & ML-1 & 143 & 7.14 & $3.25 \mathrm{E}-07$ & 1.6 & 19 \\
\hline & ML-2 & 301 & 7.99 & $3.46 \mathrm{E}-07$ & 1.8 & 10 \\
\hline & ML-3 & 302 & 5.59 & $4.43 \mathrm{E}-06$ & 2.0 & 11 \\
\hline & ML-4 & 317 & 6.50 & $7.75 \mathrm{E}-06$ & 0.7 & 15 \\
\hline \multirow{7}{*}{$\begin{array}{c}\text { Clayey } \\
\text { Sand, SC }\end{array}$} & $\mathrm{SC}-\mathrm{a}$ & NA & 0 & 7.39E-06 & 0.7 & 9 \\
\hline & SC-b & NA & 0 & $6.14 \mathrm{E}-06$ & - & - \\
\hline & SC-c & NA & 0 & $3.77 \mathrm{E}-06$ & - & - \\
\hline & SC-1 & 177 & 8.69 & $9.47 \mathrm{E}-06$ & 0.8 & 21 \\
\hline & SC-2 & 222 & 5.85 & $5.80 \mathrm{E}-06$ & 0.9 & 24 \\
\hline & SC-3 & 303 & 5.49 & $3.68 \mathrm{E}-06$ & 0.9 & 13 \\
\hline & SC-4 & 60 & 5.71 & 4.02E-07 & 0.8 & 14 \\
\hline
\end{tabular}


Table 3 Statistical parameters used for confidence interval calculation

\begin{tabular}{|c|c|c|c|c|}
\hline Test group & $\begin{array}{c}\text { Root biomass } \\
\text { per unit } \\
\text { volume of soil, } \\
\mathrm{kg} / \mathrm{m}^{3}\end{array}$ & $\begin{array}{c}\text { Standard } \\
\text { deviation of } \\
\log \mathrm{k}(\mathrm{m} / \mathrm{s}), \mathrm{s}\end{array}$ & $\begin{array}{c}\text { Sample number, } \\
\text { Standard error, }\end{array}$ & $\frac{s}{\sqrt{n}}$ \\
\hline ML-a, ML-b, ML-c & 0 & 0.132 & 3 & 0.0762 \\
\hline ML-1, ML-2 & 7.14 to 7.99 & 0.019 & 2 & 0.0136 \\
\hline ML-3, ML-4 & 5.59 to 6.5 & 0.172 & 2 & 0.1214 \\
\hline SC-a, SC-b, SC-c & 0 & 0.151 & 3 & 0.3580 \\
\hline SC-2, SC-3, SC-4 & 5.49 to 5.85 & 0.620 & 3 & \\
\hline
\end{tabular}

